\section{Efeitos e impasses do desenvolvimento}

Carlos Antonio COSTA RIBEIRO. Estrutura de classe e mobilidade social no Brasil. Bauru, SP, Edusc/ Anpocs, 2007, 370 p.

\section{André Botelho}

Como, a partir da segunda metade do século $\mathrm{XX}$, articularam-se, na sociedade brasileira, índices elevados de desenvolvimento econômico, de desigualdade de condições de vida e de oportunidades de mobilidade social? Esta é a pergunta central de Estrutura de classe e mobilidade social no Brasil. Pergunta que, como o autor explicita, parece mesmo encerrar um paradoxo, pois "se o desenvolvimento [econômico] veio acompanhado de aumento da mobilidade social, por que ainda há tanta desigualdade?" (p. 33).

Originalmente formulado como tese de doutorado defendida em 2002 no Departamento de Sociologia da Columbia University, sob orientação de Charles Tilly, e vencedora, no ano seguinte, do concurso Edusc-Anpocs, Estrutura de classe e mobilidade social no Brasil pode ser lido, num plano geral, como uma resposta especificamente sociológica à problemática do desenvolvimento brasileiro, cuja trajetória nos marca estruturalmente desde meados do século XX. Daí, o alcance e o interesse sem dúvida mais amplos do livro, além das contribuições que traz à área específica em que foi formulado, tendo em vista o seu correspondente debate contemporâneo, como mostra o prefácio escrito por Nelson do Valle e Silva. Carlos Antonio Costa Ribeiro articula, de um lado, "desigualdades sociais" e "mobilidade" à "estrutura de classes ou ocupacional" - categorias analíticas distintas, mas relacionadas, embora mesmo nas pesquisas brasileiras não sejam, em geral, mobilizadas em conjunto e de uma perspectiva integrada $-;{ }^{1}$ e, de outro, "origem de classe" a "destino de classe" para especificar os padrões de mobilidade intergeracional vigentes na sociedade brasileira ao longo do século XX - antes, durante e após o período auge de urbanização, industrialização e crescimento econômico.

Ao núcleo original da tese, como esclarece o autor na apresentação do livro, foi acrescentado, com base em pesquisas subseqüentes, dois novos capítulos - um sobre a mobilidade social de mulheres via mercado de trabalho e mercado matrimonial ou casamento (Capítulo 4), outro sobre mobilidade social no Brasil em perspectiva comparada (Capítulo 5); além disso, o texto da tese foi não apenas traduzido como substancialmente reescrito, tendo inclusive dois de seus capítulos fundidos. Na versão que chega às mãos do leitor, são duas as principais alterações analíticas que, ao lado dos novos capítulos, procuram aperfeiçoar a explicação dos padrões de estratificação social e de mobilidade na sociedade brasileira: (1) a ampliação (Capítulo 2) de onze para dezesseis categorias de classe com o intuito de permitir, como assinala o autor, a distinção de setores "modernos" e "tradicionais" entre os trabalhadores manuais urbanos e (2) a introdução (Capítulos 3 e 4) dos efeitos da expansão educacional nos padrões de mobilidade intergeracional para demonstrar o mecanismo que levou à diminuição das desigualdades de oportunidades no Brasil.

Considerado num plano sociológico mais amplo, o êxito da análise dos efeitos e dos impasses sociológicos do desenvolvimento econômico reside na capacidade que o autor demonstra em articular sistematicamente as dimensões histórica, teórica e empírica dos fenômenos sociais que toma por objeto - tratados tanto quantitativa como qualitativamente. Na sua dimensão empírica, Costa Ribeiro mobiliza dados das Pesquisas Nacionais por Amostragem de Domicílios - PNAD de 1973, 1982, 1988 e 1996, coletadas pelo Instituto Brasileiro de Geografia e Estatística - IBGE. Perscrutando as informações sobre ocupação do pai do respondente e ocupação do próprio respondente no ano da pesquisa, bem como sobre renda familiar, educação e serviços públicos que servem os domicílios e os padrões de consumo, o autor analisa a associação entre classes de origem e de destino e os padrões de mobilidade social. Assim tratadas, estas e outras informações das PNADs permitem a Costa Ribeiro analisar dados que, em primeiro lugar, compreendem fenômenos sociais transcorridos praticamente durante um século, do final do século XIX ao final do XX, e, em segundo lugar, especificar suas correlações com períodos de grande crescimento econômico (dados de 1973 e 1982) e de estagnação (bancos de dados de 1988 e 1996). 
$\mathrm{Na}$ dimensão histórica da análise, como se pode ler particularmente no primeiro capítulo, o autor rediscute características macrossociológicas cruciais das mudanças sociais ocorridas no Brasil ao longo do século XX, com destaque para os processos de transição acelerada do rural ao urbano, de industrialização por substituição de importações e de "desenvolvimento" econômico. Não se trata de compor meramente um pano de fundo, mas antes um "contexto" a partir do qual os processos de mobilidade social e de produção e reprodução de desigualdades sociais analisados no livro ganham perspectiva e, portanto, inteligibilidade histórico-sociológica. Como assinala Costa Ribeiro, são três as principias conseqüências contemporâneas do modo "incompleto" pelo qual as mudanças sociais se processaram na sociedade brasileira a partir de meados do século XX. Primeiro, a "herança rural" da população brasileira, isto é, o fato de a maioria das pessoas no mercado de trabalho ter origem nas classes de trabalhadores rurais, o que, se não é um problema em si mesmo, como o autor argumenta, representa enorme desvantagem no caso brasileiro, em virtude de nossa estrutura agrária historicamente marcada por concentração de terras e riquezas. Daí que entre os filhos de trabalhadores rurais, apenas 1,1\% tenha atingido posições de "profissionais qualificados, a mais alta hierarquia de classes" contra 60\% que permaneceu em ocupações "manuais nãoqualificadas" (p. 61). Segundo, a falta de recursos educacionais que dificulta a mobilidade social, já que, segundo sustenta Costa Ribeiro, a escolarização pode ser uma das principais vias de ascensão social e de superação de desvantagens herdadas, como ocorre com os filhos de trabalhadores rurais que não puderam contar com um sistema educacional abrangente e eficiente para sua qualificação mesmo entre as décadas de 1950 e 1970, no auge do "desenvolvimento" do país. Por fim, Costa Ribeiro aponta a manutenção da convivência entre setores tradicionais e modernos no mercado de trabalho, a qual define, em grande medida, as características das classes de destino. A esse respeito, o autor enfatiza a capacidade de as classes médias e altas assegurarem mediante numerosos mecanismos institucionais e políticos privilégios em relação às outras classes; capacidade esta as- sociada, por sua vez, a condições sócio-históricas mais amplas - como o contingente populacional brasileiro e, sobretudo, o tipo de mercado que se desenvolveu - que permitiram que se prescindisse da inclusão de maior contingente para sustentar o desenvolvimento acelerado: "Tendo em vista que o Brasil tem uma população enorme, o pequeno porcentual de pessoas nas classes mais altas (em trono de 30\% da população) corresponde a um número enorme, mais ou menos 21 milhões de pessoas em 1970, que constitui um mercado consumidor de alto nível capaz de garantir altas taxas de crescimento durante boa parte do século" ( $p$. 63). São essas as principais conseqüências histórico-sociológicas da modernização conservadora brasileira que exerceram forte impacto sobre as chances de mobilidade social.

Especificados os condicionantes históricosociológicos próprios à sociedade brasileira, Costa Ribeiro sustenta, como se pode ler nos segundo e terceiro capítulos, com base em uma minuciosa revisão da bibliografia clássica e contemporânea, a validade teórica da tese segundo a qual as bases das desigualdades sociais se encontram na estrutura de classes. Lembrando que não há consenso empírico e sequer teórico quanto à conceituação de classes sociais, o autor adota uma "abordagem mais pragmática", construída com base em "um esquema de classes que facilita comparações internacionais [Capítulo 5], não fere as particularidades relativas a certas ocupações existentes no mercado de trabalho brasileiro e é amplamente utilizado e conhecido por pesquisadores da área de estratificação social" (p. 106). Tal "pragmatismo", no entanto, não exime o autor de enfrentar teoricamente o desafio de sustentar consistentemente sua posição, o que cria no livro uma coerência teóricometodológica embasada, sobretudo, nos principais aspectos do debate contemporâneo travado entre os chamados neomarxistas, como Erik Olin Wright, e neo-weberianos, como John Goldthorpe. É a esta última tradição intelectual que a análise de Costa Ribeiro dos padrões de mobilidade social da sociedade brasileira se filia, uma vez que, segundo o autor, a concepção neo-weberiana de classe social permite medir diferenças nas chances de vida e suas relações complexas com a estrutura de classes. Filiação criativa, no entanto, porque não se trata de mera adoção de um modelo analítico 
definido a priori e sua aplicação mecânica à realidade social brasileira.

Ainda na dimensão teórica, mas especificamente em relação à literatura sociológica brasileira sobre mobilidade social, Costa Ribeiro realiza, como se pode ler no terceiro capítulo, um balanço sistemático tanto da expansão das oportunidades de mobilidade social como das desigualdades de oportunidade entre 1973 e 1996. Demarcando os avanços da perspectiva adotada no livro - cuja sistematização é apresentada num quadro onde estão resumidas as principais diferenças entre a sua pesquisa e as anteriores (p. 163) -, destaca-se, entre as principais conclusões do capítulo, a identificação e a explicação do declínio da mobilidade ascendente e o aumento da descendente como efeitos estruturais e de associação entre classes de origem e destino, ou "fluidez social", no Brasil entre 1973 e 1996.

Em suma, e neste ponto reside uma das forças de Estrutura de classe e mobilidade social no Brasil, a discussão teórica sobre as diferentes abordagens da estrutura de classe e mobilidade social não apenas, como assinalado anteriormente, não se limita à legitimação de um partido teóricometodológico, como ainda - ou talvez por isso mesmo - procura tirar conseqüências das particularidades históricas da sociedade brasileira e também dos dados empíricos disponíveis para repensar a própria teoria sociológica. Um dos principais resultados nesse sentido diz respeito à ampliação das onze categorias de classes sociais previstas no "esquema de classes Casmin" - adotado em análises neo-weberianas, em geral, e, portanto, também no livro em questão - para dezesseis, com objetivo de dar conta de distinções importantes dentro da estrutura de classes brasileira, especialmente em relação à classe trabalhadora. Não se trata da contestação desse esquema, mas de sua ampliação, justificada por Costa Ribeiro pelo fato de ele ter sido originalmente "formulado para analisar a mobilidade social em países europeus de industrialização avançada", nos quais, diferentemente do Brasil, "há muita diferenciação entre as classes de trabalho não-manual e pouca diferenciação naquelas de trabalho manual" (p. 144). Com efeito, uma interpelação à teoria sociológica que encontra inteligibilidade justamente na articulação bem-sucedida entre as dimensões histórica, teóri- ca e empírica de Estrutura de classe e mobilidade social no Brasil.

Um último aspecto a ser destacado é a aproximação da pesquisa em pauta com as reflexões de Florestan Fernandes sobre desigualdades sociais, cuja especificidade, como o autor assinala, "é o ponto de partida estrutural, ou seja, parte da idéia de que as bases das desigualdades sociais encontram-se na estrutura de classes" (p. 101). Observando que a validade empírica dos argumentos teóricos e históricos de Florestan foi pouco testada, Costa Ribeiro propõe-se "avançar com mais rigor algumas das proposições de Florestan Fernandes" (p. 104), corrigindo-as e renovando-as. Tal associação certamente procede, e tem relevância especial se nos lembrarmos que, no Brasil, a vida intelectual parece estar sempre recomeçando do zero a cada nova geração, uma vez que o "apetite" pela produção mais recente e prestigiosa - em geral estrangeira - traz freqüentemente como contrapartida o desinteresse pela produção das gerações anteriores, o que acarreta drásticas descontinuidades à reflexão. ${ }^{2}$

Além do ponto de partida estrutural assinalado, pode-se observar ainda a afinidade da análise de Costa Ribeiro com a proposição históricocomparada de Florestan Fernandes sobre as conseqüências duradouras da articulação, no Brasil, entre princípios distintos de organização social, o "estamento" e a "classe", que a rigor, isto é, nas experiências clássicas de transição para a modernidade, pareciam incompatíveis. ${ }^{3}$ Proposição que está na base do argumento mais amplo de Florestan de que "os problemas do Brasil, vistos sociologicamente, não são 'problemas de crescimento'. Crescimento tem havido, especialmente ao nível econômico. Ele não chegou a assumir, porém, as proporções e um padrão que afetassem a integração do Brasil como uma sociedade nacional e sua posição no conjunto das demais sociedades nacionais que compartilham da mesma civilização". Argumento especificamente sociológico e criticamente renovado em Estrutura de classe e mobilidade social no Brasil. Desse modo, o livro oferece novas categorias de entendimento e explicação dos complexos meandros das desigualdades sociais no Brasil durante o século XX, sem se furtar a nos alertar para os custos sociais da postergação, hoje, de mudanças políticas efetivas, visando ao 
igualitarismo, sem o que a modernização continuará não se traduzindo em modernidade.

\section{Notas}

1 Ver os balanços realizados por Antonio S. Guimarães, "Classes sociais", em Sergio Miceli [org.], O que ler na ciência social brasileira, São Paulo/ Brasília, Anpocs/Sumaré/Capes, 1999, vol. 2, pp. 13-56, e Nelson do V. e Silva, "Mobilidade social", em Sergio Miceli [org.], O que ler na ciência social brasileira. São Paulo/Brasília, Anpocs/Sumaré/ Capes, 1999, vol. 2, pp. 57-94.

2 Cf. Roberto Schwarz, "Nacional por subtração", em Schwarz, Que boras são? Ensaios, São Paulo, Companhia das Letras, 1987.

3 Cf. Gabriel Cohn, "Florestan Fernandes: a revolução burguesa no Brasil", em L. D. Mota (org.), Introdução ao Brasil: um banquete no trópico, São Paulo, Senac, 1999, pp. 398-399.

4 Cf. Florestan Fernandes, Sociedade de classes $e$ subdesenvolvimento, Rio de Janeiro, Zahar, 1981, p. 173 .

André BOTELHO é professor do Programa de Pós-graduação em Sociologia e Antropologia - PPGSA/IFCS/UFRJ. Autor, entre outros, de O moderno em questão: a década de 1950 no Brasil (Topbooks, no prelo, em colaboração). E-mail: andrebotelho@digirotas.com.br.

\section{Vicissitudes de uma análise de survey à brasileira}

Alberto Carlos ALMEIDA. A cabeça do brasileiro. Rio de Janeiro, Record, 2007. 277 páginas.

\section{Fabricio Mendes Fialho}

A cabeça do brasileiro já nasce com ares de best seller: imediatamente após seu lançamento, o livro foi tema de uma matéria de oito páginas na revista de maior circulação do país ${ }^{1}$ e seu autor convidado para discuti-lo em um dos mais prestigiosos programas brasileiros de entrevistas. ${ }^{2}$ Virtude para tal visibilidade não falta ao livro. Trata-se, talvez, de uma das primeiras tentativas de mapeamento das opiniões, dos costumes e das "visões de mundo" da população brasileira em sua totalidade. E, não bastasse ser uma das obras pioneiras neste sentido, pretende-se como das mais abrangentes, cobrindo uma série de tópicos ao longo de suas quase trezentas páginas. Tal tipo de pesquisa, bastante comum nos Estados Unidos há algumas décadas, ainda é rara no Brasil. E se espera que esta seja a primeira de diversas outras. Afinal, muito já se escreveu sobre o "caráter" do brasileiro, seus padrões de comportamento e opinião, mas pouco ainda foi investigado a respeito em pesquisas empíricas.

O empreendimento de Alberto Almeida é, nesse sentido, louvável. Utilizando-se de dados da Pesquisa Social Brasileira ${ }^{3}$ realizada em 2002, o autor pretende realizar uma grande radiografia da forma como o brasileiro vê o mundo e as pessoas ao seu redor, de como entende a definição dos rumos de sua vida e soluciona situações de impasse, de como se relaciona com o mundo da política e da economia, valora e julga comportamentos, classifica indivíduos, entre diversas outras situações. Sua proposta consiste em uma tentativa de verificação empírica das teses de Roberto DaMatta sobre a sociedade brasileira e do que a torna tão peculiar. Nada mais apropriado e merecido, uma vez que DaMatta é autor de uma das obras mais originais e instigantes a respeito do Brasil, mas que ainda não tivera suas proposições testadas empiricamente em estudos com pretensões de 